\title{
As mídias como ferramenta pedagógica para o Ensino de Ciências: uma experiência na formação de professores de nível médio
}

\section{The media as a pedagogical tool for the teaching of science: an experience in teacher training}

Ana Paula Inacio Diório ${ }^{1}$ | anapdiorio@gmail.com

Giselle Rôças

\section{RESUMO}

O presente artigo trata de uma pesquisa empírica com foco no Ensino de Ciências, realizada numa escola pública de formação de professores em nível médio localizada na região metropolitana do Rio de Janeiro. A pesquisa, cuja investigação se deu acerca da utilização das mídias na sala aula como ferramenta pedagógica, foi desenvolvido com um grupo de 11 alunos através de um ciclo de oficinas que foram realizadas em julho de 2011. O emprego de uma metodologia do tipo participante permitiu incentivar um método de trabalho voltado para uma construção dialógica e a discussão dos impactos esperados, os quais se relacionam às questões educacional, tecnológica, científica e social. Os resultados apontam que as mídias podem ser empregadas como ferramenta pedagógica e contribuir para ensino de ciências e, consequentemente, para a alfabetização científica.

Palavras-chave: Mídia.Alfabetização científica. Formação de Professores.

\footnotetext{
1 - Programa de Pós-graduação Ensino de Ciências- PROPEC do Instituto Federal de Educação, Ciência e Tecnologia do Rio de Janeiro - IFRJ. Mestrado Profissional em Ensino de Ciências - Rua Lúcio Tavares, 1045, Centro, Nilópolis. CEP: 26530-060 Telefone: (21) 2691-9826

2 - Instituto Federal de Educação, Ciência e Tecnologia do Rio de Janeiro, Campus Nilópolis (IFRJ)
} 


\section{ABSTRACT}

This article discusses an empirical research focused on the issues involved in teaching Science. The research was performed at a public school, high school level, located in the metropolitan area of Rio de Janeiro. This project, whose research focuses on the utilization of media in a classroom as a pedagogical tool, was developed by a group of 11 students through workshops that was take place in July 2011. The use of a participant design methodology allowed to encourage the method of working towards a dialogical construction and the discussion about the expected impacts, which are related to educational, technological, scientific and social issues. The results show that the media can be used as a pedagogical tool and can contribute to science teaching and, consequently, to scientific literacy.

Keywords: Media. Scientific literacy. Science learn. 


\section{INTRODUÇÃO}

Dentro de uma sociedade dinâmica e informatizada, como a que vivemos, a importância das transformações nos processos educacionais são constantemente discutidas pelos pesquisadores do campo de ensino e educação. Osborne (2007) destaca a importância da capacidade de pensar e aprender, a qual é altamente maleável e pode se desenvolver através da educação cujo propósito não deve ser a triagem de pessoas pelos talentos e capacidades que eles já têm, mas o de desenvolver e melhorar suas habilidades.

Muitos pesquisadores têm defendido o surgimento de uma nova geração, batizada de "Geração Digital" também conhecida como "Geração On-Line”, “Geração Internet”, “Geração Conectada”, “Geração Z” (de zapping) ou "Geração Pontocom”, a qual, desde muito cedo, trava contato e convive com tecnologias como celulares, computadores e tantos outros aparatos tecnológicos, os quais "têm contribuído na produção de uma vida inteiramente diferenciada daquela de representantes das gerações anteriores” (FILHO E LEMOS, p.17, 2008).

Neste contexto, uma característica importante da vida moderna é o crescimento das tecnologias de comunicação, ou seja, o telefone móvel e a internet com acesso a uma gama muito maior de fontes de informação (BUCKINGHAM, 2000; SEFTON-GREEN, 2007). Tais tecnologias permitem mais autonomia e possibilitam a auto-expressão e a construção da identidade, Myspace e Facebook, os sites de redes sociais são exemplos arquetípicos. Sendo assim, o conhecimento para a juventude de hoje se torna um objeto a ser adquirido como e quando ele é necessário através da interação social e dialógica em vez de recepção passiva. Logo, o contexto de mudança cultural torna questionáveis as instituições escolares cujo valor tem de ser demonstrado e onde o professor e os textos não são mais a única fonte de conhecimento, mas um de muitos (OSBORNE, 2007).

Para Belloni (2005) o reflexo do avanço tecnológico (compreendido como processo social) sobre os processos e instituições sociais (educação, comunicação, trabalho, lazer, relações pessoais e familiares, cultura, imaginário e identidade etc.) tem sido muito forte, embora percebido de modos diversos e estudado a partir de diferentes óticas. Nesse contexto, para que a sociedade da informação seja participativa e plural é importante que os cidadãos sejam alfabetizados cientificamente, ou seja, tenham competência para compreender as informações e não somente fazer a leitura das palavras, é preciso que sejam capazes de fazer uma leitura crítica da mídia e se apropriar desses conhecimentos para o exercício da cidadania."Poderíamos considerar alfabetização científica como o conjunto de conhecimentos que facilitam aos homens e mulheres fazer uma leitura do mundo onde vivem” (CHASSOT, 2006, p. 38).

Krasilchik e Marandino (2006, p.22) ainda defendem que além de serem alfabetizados é importante que os cidadãos sejam letrados cientificamente, o que significa "não só saber ler e escrever sobre ciência, mas cultivar e exercer as práticas sociais envolvidas com a ciência, ou seja, fazer parte da cultura cientifica”.

A discussão acerca da introdução de tecnologias da informação - TIC - no ensino formal vem sendo levantada e defendida por autores que acreditam no seu potencial reestruturador do currículo e redefinidor de práticas pedagógicas (MARTINHO E POMBO, 2009). De acordo com esses autores as TIC, podem ser transformadoras na educação em ciências quando utilizadas de forma adequada. Além disso, "os sistemas educativos devem dar resposta aos múltiplos desafios das sociedades da informação, na perspectiva de um enriquecimento contínuo dos saberes e do exercício de uma cidadania adaptada às exigências do nosso tempo" (UNESCO, 1996, p.59).

Nesse contexto, o educador possui um importante papel, pois com o uso das TIC o professor "terá de refletir sobre as várias formas de construção do conhecimento. Por isto, deverá repensar a metodologia e o processo ensino-aprendizagem num ambiente interativo e dinâmico" (Barroqueiro et al, 2009, p.6). Logo, a utilização das tecnologias requer um planejamento adequado das atividades e uma proposta pedagógica voltada para a interação entre o aluno e o processo de ensino aprendizagem. 
Diante disso, a escola tem o importante papel de despertar o interesse dos indivíduos para as ciências e para isso pode lançar mão de atividades que os envolva e os tornem capazes de usar os conhecimentos adquiridos em novas situações. Portanto, uma educação com as mídias é uma maneira da escola contribuir para a formação de indivíduos que se apropriem de forma crítica da mídia-educação, principalmente, para aprender/ compreender ciências.

Moreira defende que os meios de comunicação exercem hoje uma "função pedagógica básica: a de socializar os indivíduos e de transmitir-lhes os códigos de funcionamento do mundo e que as instituições como a família, a escola e a religião continuam sendo as fontes primárias da educação e da formação das crianças” (MOREIRA, 2003, p.1216).

Entretanto, não se pode negar a influência da mídia através dessas instituições. Sendo assim, desenvolver atividades com mídias em sala pode ser mostrar importante para aproximar os alunos de uma realidade que muitos já conhecem, mas não sabem fazer uma leitura crítica e nem se apropriar disso para a construção do conhecimento.

É importante que atividades com mídias sejam desenvolvidas visto que, como destaca Caldas (2006), aprender a ler as mídias e conseguir compreender a mensagem além das aparências da narrativa jornalística, é um trabalho difícil, mas desejável para uma leitura crítica. E por isso, capacitar professores e alunos se mostra cada vez mais relevante para que o discurso da imprensa seja compreendido, principalmente, diante de uma mídia que se revela como meio de divulgação científica.

Seguindo o viés descrito, a pesquisa em questão teve como principal objetivo investigar a contribuição que o desenvolvimento de atividades pedagógicas com as mídias impressa e digital conferiu para a sensibilização de futuros professores, na perspectiva do Ensino de Ciências. Além de despertar nos alunos o interesse para desenvolver atividades em sala de aula que contribuam para alfabetização científica e uma educação em ciências como prática social.

\section{DESENHO METODOLÓGICO}

Esse trabalho representa parte de uma pesquisa de conclusão do curso de mestrado profissional em Ensino de Ciências do Instituto Federal de Educação do Rio de Janeiro (IFRJ). E o local de intervenção e estudo foi o Instituto Estadual de Educação Governador Roberto da Silveira (IEGRS), localizado em Duque de Caxias, na região metropolitana do Estado do Rio de Janeiro, que apresenta um IDEB de 2.8, ficando abaixo do projetado (3.1) para o segundo ciclo do Ensino Fundamental no ano de 2009. Tomando o ENEM como outro parâmetro, tal município também apresenta baixos índices para o Ensino Médio Regular. Aliado a isso, a escolha do instituto deveu-se, também, ao fato de ser uma das escolas públicas estaduais que ainda forma professores em nível médio.

A pesquisa foi dividida em duas etapas denominadas de "Encontros" (os resultados, referentes aos "Encontros” da primeira etapa, foram apresentados no VIII ENPEC- Encontro Nacional de Pesquisa em Educação em Ciências - I CIEC I Congreso Iberoamericano de Investigación en Enseñanza de las Ciencias), os quais ocorreram no Instituto Estadual Governador Roberto da Silveira, em Duque de Caxias e as "Oficinas", as quais ocorreram no Instituto Federal de Educação (IFRJ) e são o foco desse estudo. O contato com os 19 alunos selecionados para participarem das atividades teve início em fevereiro de 2011. O critério de seleção dos participantes foi discutido em conjunto com a coordenadora pedagógica do curso normal, já que a mesma possuía conhecimento da estrutura curso, das propostas interdisciplinares desenvolvidas por professores e alunos dentro da escola e do grau de envolvimento dos mesmos. Desta forma, foram estabelecidos três elementos-chave para a seleção dos alunos, a saber: 1) vinculação com as licenciaturas na área de ensino de ciências, as quais são ofertadas no instituto federal de educação, com o objetivo de despertar o interesse nos alunos em cursar uma delas; 2) participação nos projetos pedagógicos interdisciplinares desenvolvidos pela escola; 3) notas. Foram escolhidos dez alunos do $3^{\circ}$ ano e dez do $4^{\circ}$ ano normal. 
A pesquisa já havia sido aprovada pelo Comitê de ética em pesquisa (CEP) do IFRJ, registrado no CONEP/CNS/MS sob Ofício n ${ }^{\circ} 2203$. Além disso, todos os participantes assinaram termo de ciência e autorização para participação na pesquisa, uso da imagem, voz e textos com fins de divulgação científica e autorização para saídas de campo, no caso de menores os termos foram assinados pelos responsáveis.

Após o contato inicial para apresentação dos participantes aos responsáveis pelo desenvolvimento da pesquisa, 19 alunos se inscreveram nos encontros, que começaram na semana seguinte. $O$ grupo era composto por alunos do $3^{\circ}$ e $4^{\circ}$ ano do curso de formação de professores, com faixa etária entre 16 a 18 anos, sendo a maioria dos participantes do sexo feminino. Os seis encontros ${ }^{1}$ quinzenais, que antecederam as oficinas, ocorreram entre 20/02/11 e 09/06/11, todos voltados para a discussão da introdução da mídia como ferramenta pedagógica, foram uma maneira de aproximação/ familiarização dos professores pesquisadores com o grupo e do grupo com o tema, permitindo a todos o preparo e desenvolvimento de atividades que tiveram sua culminância nas oficinas de julho de 2011.

A metodologia empregada na pesquisa foi do tipo participante, por considerarmos o envolvimento dos sujeitos passo fundamental para a realização de projetos comprometidos com o desenvolvimento e com o saber humano. Thiollent (2005) defende que a pesquisa participante pode desempenhar um papel importante nos estudos e contribuir para a aprendizagem do pesquisador e de todas as pessoas ou grupos envolvidos em situações de problemas acerca da pesquisa. $\mathrm{O}$ autor destaca que essa proposta tem como um dos principais objetivos fornecer aos envolvidos maneiras para que possam responder de forma eficiente e transformadora aos problemas da condição na qual se encontram.

\section{Primeira oficina, dia 30 de junho de 2011}

Com onze alunos presentes a oficina inicial foi realizada em duas etapas. Na primeira, com quatro horas de duração foi discutido com o grupo o que é um artigo científico, como ele é construído e sua importância como forma de divulgação da ciência e conseqüentemente uma fonte interessante de consulta e pesquisa para o professor.

Depois dessa discussão os alunos se dividiram em quatro grupos e os seguintes artigos foram distribuídos aleatoriamente: 1- “Trilogia: Química, Sociedade e Consumo” (OLIVEIRA, MARTINS E APPELT, 2010); 2- Contribuições da Química Inorgânica para a Química Medicinal (BERALDO, 2005); 3- "A evolução da atmosfera terrestre” (JARDIM, 2001); 4- “A Química a serviço da humanidade” (SILVA E ANDRADE, 2003).

Todos os artigos eram da revista "Química nova na escola". A escolha dessa revista eletrônica foi motivada pelo fato de muitos artigos serem voltados para a sala de aula, além de serem curtos (favorecendo o melhor uso do tempo) e possuírem uma linguagem adequada ao público alvo.

No primeiro momento os grupos foram orientados a lerem os artigos e discutirem entre eles o conteúdo dos mesmos, o formato, a diagramação e anotar todas as características que julgavam relevantes. Sendo que a proposta era voltada para que os alunos pensassem numa maneira de adaptar aquele assunto às séries iniciais.

No segundo momento da oficina, também com quatro horas de duração, os grupos foram orientados a construírem textos a partir dos conteúdos dos artigos, os quais deveriam ser uma releitura do tema de forma simplificada. Os alunos transformariam o texto científico num texto com uma linguagem acessível a alunos do ensino fundamental. Todos os grupos construíram e apresentaram e discutiram os textos ao final da oficina (Figuras 1 e 2). 


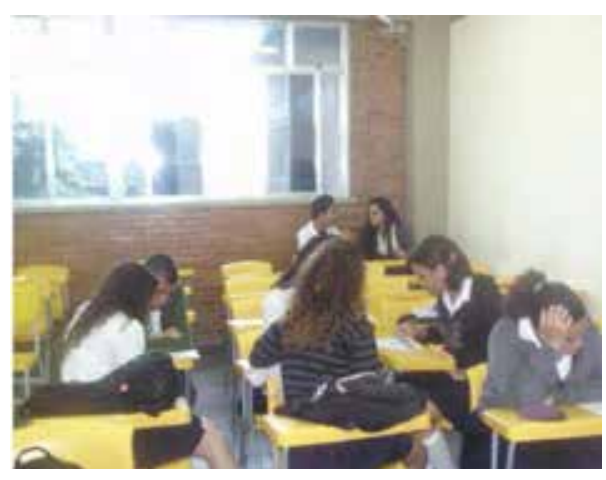

Figura 1: atividade com artigo científico - Foto da autora

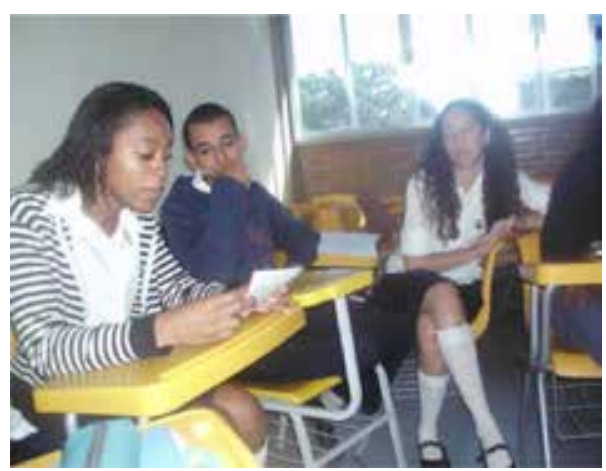

Figura 2: alunos apresentando a discussão do artigo - Foto da autora

\section{Segunda oficina, dia 11 de julho de 2011}

Também com onze alunos presentes, foi realizada a segunda oficina em uma etapa, com 4 horas de duração. Esse encontro aconteceu no Laboratório de Estratégias Didáticas (LED), do curso de Produção Cultural do IFRJ, os alunos puderam editar um documentário que eles filmaram no IEGRS em um das nossas atividades que havia sido realizada na escola durantes os primeiros encontros com o grupo.

Os alunos tiveram a orientação de dois monitores/estagiários, estudantes do curso de Produção Cultura, que os instruíram na utilização do Windows Movie Maker para editar toda a filmagem e personalizar o DVD, o qual se transformou num produto final dos encontros sobre mídia-educação, cujas cópias foram impressas pelos monitores do LED e apresentadas na feira-ciências da escola. (Figura 3 e 4). 

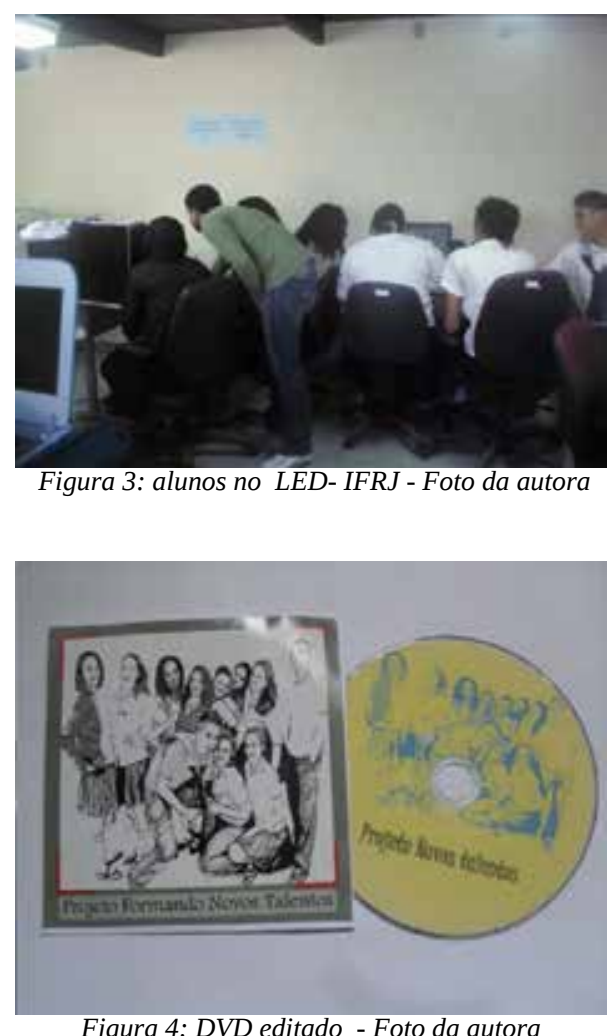

Figura 4: DVD editado - Foto da autora

\section{Terceira oficina, dia 13 de julho de 2011}

Com os mesmos alunos presentes, foi realizada em uma etapa, com quatro horas de duração. Na última oficina, foi realizada uma atividade com mídia impressa, na qual os alunos foram orientados a escolherem, individualmente, uma foto de um jornal, no caderno de Ciência, recortá-la e anotar o nome na foto e no jornal do qual ela foi retirada. Em seguida as fotos foram misturadas e cada aluno escolheu a foto de um colega para realizar a atividade, sem saber a qual notícia aquela foto estava relacionada. A proposta foi que cada aluno construísse um título e um subtítulo para aquela imagem, apenas usando as informações icônicas.

Após a realização da atividade, eles apresentaram e discutiram a notícia original que correspondia cada foto e comparamos à construção dos alunos. A discussão foi voltada para a construção de títulos e subtítulos de textos jornalísticos e a utilização de imagens como ferramenta pedagógica, além da abordagem de como assuntos científicos são tratados pela grande mídia. (Figuras 4A e 4B). 


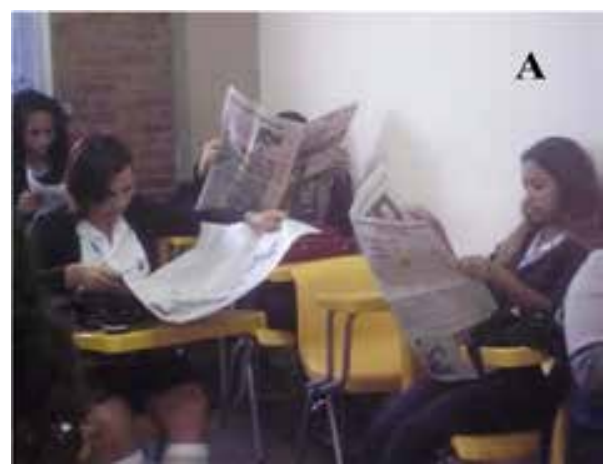

Figura 4A: Atividade com mídia impressa - Foto da autora

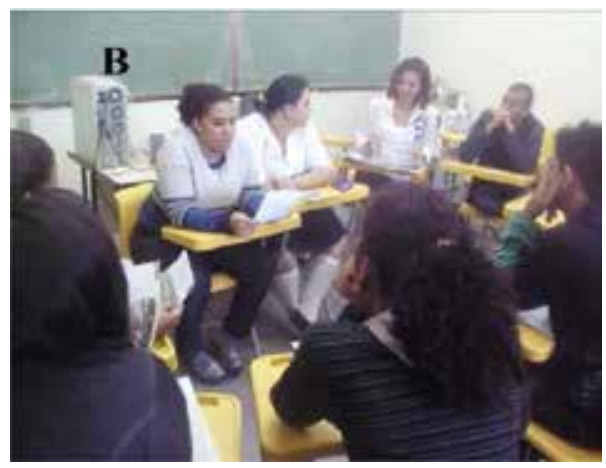

Figura 4B: Atividade com mídia impressa - Foto da autora.

No último encontro os alunos responderam um questionário referente às atividades relacionadas às mídias realizadas ao longo dos encontros. Através desse questionário foi possível analisar a aceitação do tema e da forma pela qual ele foi desenvolvido nos encontros. O questionário continha nove questões abertas, as quais estão descritas abaixo:

1- Diga em poucas palavras o que você achou das atividades realizadas.

2- Você desenvolveria alguma atividade com mídia (impressa ou digital com os seus alunos?

3- Qual a importância, na sua opinião, de se trabalhar com as mídias em sala de aula?

4- Como atividades como essas poderiam contribuir para o ensino de ciências nas escolas?

5- Você acha fácil desenvolver esse tipo de atividade com os alunos?

6- Diga com suas palavras o que é alfabetização científica.

7- Você acredita que atividades como essas poderiam contribuir para a alfabetização científica?

8- Qual a importância de que os alunos saibam ler/entender a mídia de maneira crítica?

9- Vocês acham que esse tipo de atividade pode ser aplicada com um foco em outra disciplina curricular (português, matemática, história, etc.)? 
O questionário foi tratado utilizando-se o método da análise de conteúdo descrito em Bardin (2010, p. 40), no qual diz a autora ser "[...] um conjunto de técnicas de análises das comunicações que utiliza procedimentos sistemáticos e objetivos da descrição do conteúdo das mensagens.”

De acordo com Bardin (2010) a análise de conteúdo pode ser dividida em fases diferentes, organizadas cronologicamente, são elas: a pré-análise; a exploração do material; o tratamento dos resultados, a inferência e a interpretação. Dessa forma, os principais pontos da pré-análise foram a leitura flutuante (primeiras leituras de contato com os documentos a serem analisados), a escolha dos documentos (no caso o questionário do projeto), a formulação das hipóteses e objetivos (uma afirmação provisória sobre a análise do tema e a finalidade da proposta), a referenciação dos índices e elaboração dos indicadores (a freqüência de aparecimento do tema) e a preparação do material.

Os dados foram tratados com base na técnica da análise temática ou categorial que, de acordo com Bardin (2010), baseia-se numa contagem de um ou vários temas ou itens de significação, ou seja, o desmembramento do texto em unidades com a finalidade de se descobrir os diferentes núcleos de sentido que constituem a comunicação, e posteriormente, realizar o seu reagrupamento em classes ou categorias. Além disso, a análise documental também facilitou o manuseio das informações, já que, de acordo com a autora, se constitui uma técnica que visa representar o conteúdo de um documento diferente de seu formato original.

Desse modo, seguimos as fases de análise, reunindo primeiramente o corpus do material coletado, seguida de leitura flutuante para tomar conhecimento do conteúdo do questionário. Posteriormente fizemos várias leituras com um olhar cada vez mais voltado para o objeto e objetivos da pesquisa e iniciamos a marcação e codificação das Unidades de Registro. De acordo com Bardin (2010), unidade de registro (UR), apesar de sua natureza e de dimensões variáveis, é a menor unidade semântica extraídas de um texto, podendo ser um personagem, uma palavra-chave, um tema, etc. Em seguida num esforço de síntese chegamos às unidades de significação temáticas ou Temas, para num outro esforço de síntese chegarmos às categorias. Já a última fase, do tratamento, inferência e interpretação, permitiu que os conteúdos recolhidos se constituíssem em dados quantitativos e/ou análises reflexivas, em observações individuais e gerais dos questionários.

Assim, a análise do conteúdo obtido nos depoimentos deu origem a cinquenta e três unidades de registro (URs), que foram agrupadas em nove temas. A organização dos temas por assuntos afins permitiu a criação de três categorias de análise denominadas: Mídia como ferramenta pedagógica, Facilidades e dificuldades do trabalho com mídias na escola, Abrangência da mídia educação (Quadros 1 e 2).

Quadro 1: Síntese da construção dos temas, a partir da análise de conteúdo.

\begin{tabular}{lll} 
TEMAS & N $^{\mathbf{0}}$ de U.R & \% U.R. \\
\hline Aceitação do tema mídia-educação & 10 & 18,8 \\
\hline Sentimento dos alunos acerca das atividades & 07 & 13,2 \\
\hline Contribuição das mídias para o ensino formal & 06 & 11,3 \\
\hline Dificuldade de introdução das mídias na escola & 06 & 11,3 \\
\hline Alfabetização científica & 04 & 7,5 \\
\hline Formação em cidadania & 04 & 7,5 \\
\hline Interdisciplinaridade & 05 & 9,4 \\
\hline Imagem negativa das mídias & 06 & 11,3 \\
\hline Contribuição para a formação inicial de professores & 05 & 9,4 \\
\hline Total & 53 & $100 \%$ \\
\hline
\end{tabular}

Fonte: Dados da autora. 
Quadro 2- Síntese da construção das categorias, a partir da análise de conteúdo.

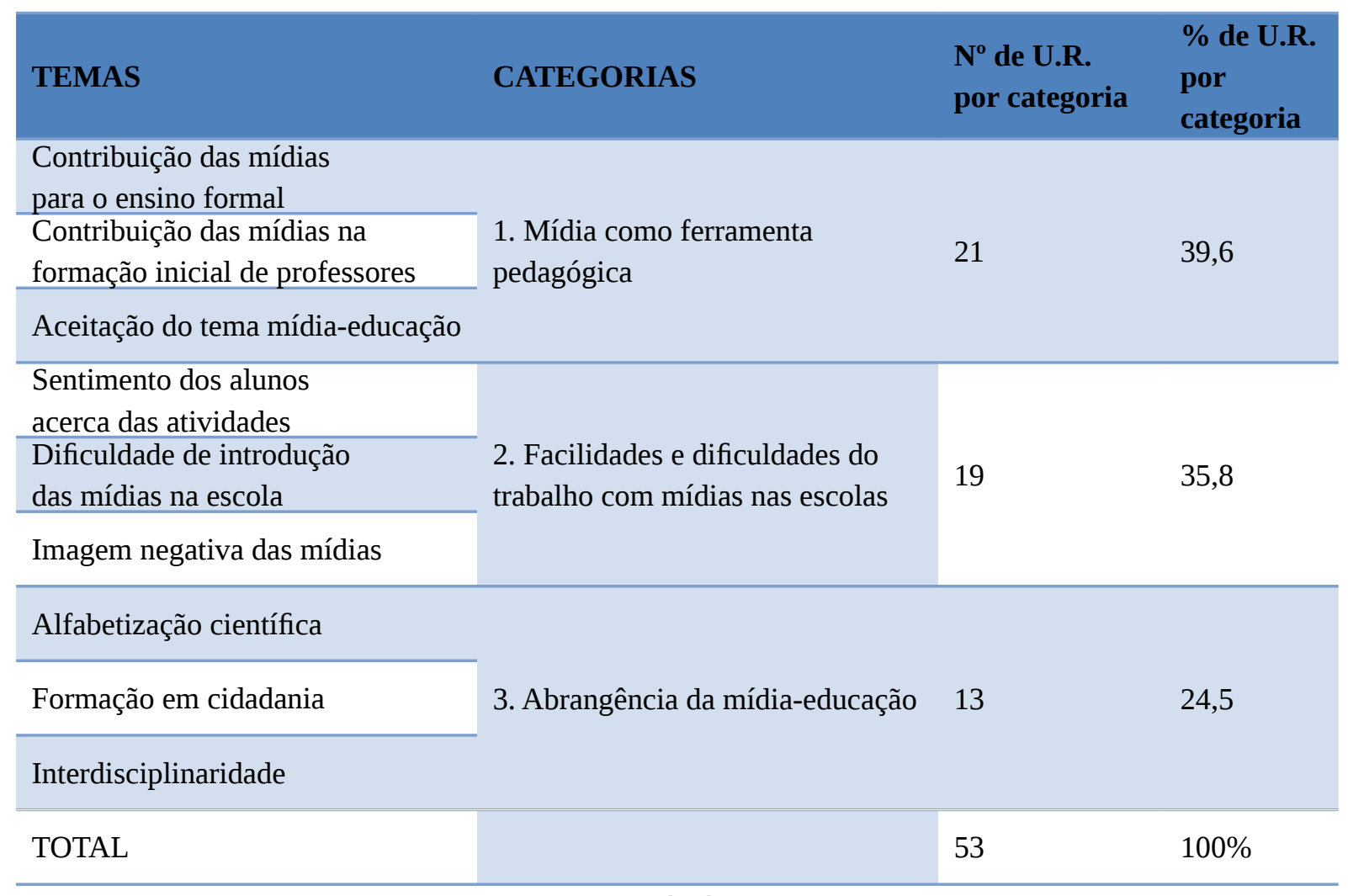

Fonte: Dados da autora

\section{ANÁLISE E DISCUSSÃO DOS RESULTADOS}

É importante destacar que o interesse da pesquisa não foi quantificar de que forma as atividades com as mídias promoveram algum tipo de aprendizado científico na condição dos participantes como alunos ou mudança de comportamento ou atitude quanto à prática pedagógica deles como professores. Porém, a motivação maior era perceber se essas atividades poderiam sensibilizá-los quanto à importância das mídias no contexto da sociedade atual, assim como descrito na literatura, e a possibilidade de enxergá-las como materiais didáticos em potencial e discutir com os participantes se as mesmas eram viáveis de serem aplicadas em sala de aula, assim como ouvir sua adaptação e transposição para outros segmentos. Além disso, um dos focos principais foi o de permitir que os alunos/professores percebessem como podem ser ativos na construção do conhecimento a partir de práticas que promovam a interação entre eles e os alunos e principalmente entre os alunos e o processo de ensino e aprendizagem.

Os resultados discutidos se assemelham aos que foram encontrados na primeira etapa da pesquisa, através dos "Encontros", cuja coleta de dados se deu através da técnica de grupo focal. Essa discussão inicial permitiu conhecer os alunos, ouvi-los e aperfeiçoar a segunda etapa.

\section{Categoria 1: mídia como ferramenta pedagógica}

O surgimento deste resultado atende um dos objetivos específicos do trabalho o qual responde, a partir das atividades desenvolvidas com os alunos-professores e dos resultados obtidos que as mídias utilizadas no presente trabalho podem ser levadas para sala de aula como mais uma ferramenta pedagógica. Nesse sentido, avaliamos as mídias em questão e sua potencialidade para o Ensino de Ciências através, principalmente, da aceitação entre os futuros professores, haja vista presença constante desses meios de comunicação num novo perfil social no qual nos encontramos: a sociedade da informação. 
Nesse contexto, Citelli (2004), reforça que o professor cada vez mais deve se mostrar como um facilitador da aprendizagem, isso porque a sala de aula disputa hoje espaços com “escolas paralelas” formados por uma rede de comunicação que envolve os alunos.

O autor também reforça a importância da mídia como ferramenta pedagógica ao colocar que a escola como espaço de socialização deve ampliar o conceito de leitura e de aprendizagem e para isso deve-se equipar melhor para entender os significados e os meios de ação das novas linguagens e para isso deve se envolver para trabalhar com as mensagens emitidas pelos meios de comunicação de massa no diz respeito à produção dos sentidos (CITELLI, 2004).

A partir do momento que identificamos através da pesquisa que as mídias possuem uma boa aceitação a partir dos professores podemos inferir que a introdução das mesmas na formação inicial, com destaque para a formação de professores de cursos normais, é uma forma de contribuir para o pensamento crítico, o qual se mostra de extrema importância para o desenvolvimento de uma sociedade mais plural e participativa, além de encorajar a reprodução dessas práticas por esses professores com suas futuras turmas.

Quando questionados se desenvolveriam alguma atividade com mídia impressa ou digital-eletrônica todos os 11 alunos responderam que sim. Como mostrado nos resultados o tema mídia na sala de aula teve boa aceitação entre os alunos do curso normal que participaram do projeto. Isso também pode ser observado através das respostas de alguns alunos a respeito da importância das mídias em sala de aula.

"A importância de trabalhar com mídias em sala de aula é despertar nos alunos o interesse de opinar, dar sugestões e se atualizarem”(Tamires, 17 anos)

O depoimento reforça a idéia que foi trabalhada com os alunos durante o desenvolvimento do projeto, o qual vai de encontro com a pedagogia freireana que defende que o aluno deve se expressar, participar ativamente das aulas e ser sujeito ativo na construção do conhecimento. Sendo assim o educador que atua de forma democrática deve reforçar a capacidade crítica do aluno, sua curiosidade e evitar sua submissão (FREIRE, 2010).

A importância da leitura crítica da mídia, assim como a alfabetização científica para a formação em cidadania também é discutida nos Parâmetros Curriculares Nacionais, de acordo com o documento

[...] conviver com produtos científicos e tecnológicos é algo hoje universal, o que não significa conhecer seus processos de produção e distribuição. Mais do que em qualquer época do passado, seja para o consumo, seja para o trabalho, cresce a necessidade de conhecimento a fim de interpretar e avaliar informações, até mesmo para poder participar e julgar decisões políticas ou divulgações científicas na mídia. A falta de informação científico-tecnológica pode comprometer a própria cidadania, deixada à mercê do mercado e da publicidade (BRASIL, 1998, p.22).

Quando defendemos a introdução das mídias na escola estamos discutindo uma forma para que essa alfabetização que se deseja seja efetiva e que, de fato, contribuía para a leitura do mundo e das próprias mídias, mas uma leitura significativa, a qual permita a discussão e a tomada de decisão a cerca de situações problemas que são proposta a todo o momento na sociedade da informação.

Ao serem questionados sobre como essas atividades poderiam contribuir para o ensino de ciências nas escolas, alguns alunos responderam:

"Iriam contribuir como uma forma alfabetizadora, ou melhor, como uma inovada forma de alfabetizar" (Priscila, 18 anos).

"Contribui de modo a incentivar os alunos a quererem compreender mais, tanto o ensino científico, quanto as outras disciplinas" (Thaiane, 17 anos). 
Apesar do pouco contato com disciplinas científicas durante o curso de formação de professores de nível médio os alunos percebem a necessidade e a importância dos conteúdos das ciências ao longo de formação. A boa aceitação dos assuntos trabalhados durante o projeto e as respostas dos mesmos a cerca da importância do ensino de ciências e a discussão de como ele pode ser introduzido nas séries iniciais deixou claro que os alunos se importam com esse assunto e se envolveram com as questões que diz respeito à alfabetização científica e como esse poderia ser promovida desde o início da vida escolar.

Ao discutir a importância da educação científica na sociedade atual Cachapuz et al. (2011) destaca que ela se tornou uma exigência urgente e num fator crucial para o desenvolvimento das pessoas e dos povos. Além disso, os autores também discutem que a epistemologia no desenvolvimento da didática das ciências e na formação dos docentes tem um papel essencial para que as visões deformadas da ciência e da tecnologia não sejam reproduzidas pelo próprio ensino e não contribuam para o insucesso escolar, a rejeição e, por fim, a pouco procura pelos cursos de nível superiores na área científica.

Sendo assim, discutir a epistemologia da ciência e a formação dos professores na área científica se faz cada vez mais necessário. E partindo da idéia que os professores dos cursos normais será os responsáveis pela iniciação da vida escolar e do primeiro contato dos alunos com as ciências é importante que a formação nos cursos normais também sejam discutidas desse âmbito.

Autores como Delizoicov, Angotti e Pernambuco (2007) destacam a emergência de mudanças no ensino de ciências, visto que a partir da década de 70, com a democratização do acesso à educação fundamental pública, a maneira simplista ingênua com que o ensino de ciências tem sido tratado tem-se agravado. Os pesquisadores abordam que a mudança do perfil do público escolar gera necessidades e demandas diversificadas e que, por conta disso, mudanças bruscas na atuação dos professores dessa área, nos diversos níveis de ensino, se faz necessário.

Portanto, os autores destacam que:

Assim, distinguindo-se de um ensino voltado predominantemente para formar cientistas, que não só direcionou o ensino de Ciências, mas ainda é fortemente presente nele, hoje é imperativo ter como pressuposto a meta de uma ciência para todos (DELIZOICOV, ANGOTTI E PERNAMBUCO, 2007, p. 34).

Quando inserimos as mídias nesse contexto de mudança e renovação do ensino de ciências, mais desafios são lançados, ou seja, introduzir novas tecnologias da comunicação na escola também é vista como um desafio do qual muitas escolas e professores não estão preparados para enfrentar.

"A inserção da escola no ecossistema comunicativo, considerando tal passagem como experiência cultural ampla, é um desafio para todos os educadores” (CITELLI, 2007, p. 35). Para o autor a escola precisa, entre as novas linguagens, meios de comunicação e aparatos técnicos, encontrar um novo lugar entre os espaços educativos no qual ela possa investir na construção do saber, do conhecer, do criar e do pensamento crítico.

Sendo assim, se há transformação real na sociedade por conta de uma nova geração, começar a repensar a escola e a possibilidade da introdução de novos meios de comunicação nas salas de aula como ferramentas pedagógicas se mostra um passo rumo a uma possível mudança, a qual precisamos começar a discutir e construir junto do ambiente escolar com a participação ativa dos alunos, dos pais, professores e da comunidade escolar como um todo. Mas, para tal precisamos de políticas e contexto social favoráveis a essa transformação.

\section{Categoria 2: facilidades e dificuldades do trabalho com mídias nas escolas.}

Apesar da boa aceitação dos alunos em relação as atividades desenvolvidas durante o projeto, ao serem questionados sobre a facilidade do trabalho com as mídias na sala de aula alguns alunos responderam que rea- 
lizar essas atividades pode não ser tão simples, ou seja, há a necessidade de um planejamento e de organização para que a atividade atinja o objetivo proposto.

"Depende de alguns fatores, sendo eles: como trabalhar e por que trabalhar. Após descobrimos o motivo e a importância das mídias na sala de aula será mais fácil de se trabalhar”(Tamires, 17 anos).

"Toda atividade que sai do padrão, quadro, papel e caneta, provém de um trabalho mais rebuscado, portanto não é fácil, mas também não é impossível” (Magda, 17 anos).

“Fácil não é, pois é mais prático manter os métodos tradicionais do que inovar em nossas aulas” (Luciano, 19 anos).

Nesse contexto, pesquisadores destacam que é importante que a mídia seja usada de forma planejada de moda a fazer sentido a cerca do assunto que o professor deseja trabalhar e além disso que desperte o interesse e para o diálogo entre os aluno e os meios de comunicação baseado na reflexão e na construção do conhecimento.

Batista (2007) destaca que ao refletirmos sobre aspectos da educação e da comunicação no contexto que nos cerca, devemos inseri-los no diálogo da escola. Segundo a autora "a utilização estruturada dos meios de comunicação por professores e alunos pode contribuir para esse diálogo caso haja uma construção da leitura critica dos meios” (BATISTA, 2007, p. 101, grifo nosso).

Além disso, a autora destaca que apesar do contexto que estamos inseridos, com avanços tecnológicos e muita informação, exigir que os educadores sejam hábeis para lidar com todos os meios de comunicação com certa naturalidade, as políticas públicas atuais, a estrutura da formação de professores e o contexto social não colaboram para que os professores acompanhem essa realidade principalmente nas escolas públicas (BATISTA, 2007).

Nesse sentido, Napolitano destaca que

\begin{abstract}
O trabalho com novas linguagens como fonte de aprendizagem torna esta questão ainda mais complicada, pois geralmente elas escapam da área de especialidade do profissional. Um professor de história, geografia ou português, por mais que se interesse por cinema, televisão ou música, não é um especialista. Obviamente, a incorporação deste tipo de fonte não pressupõe que o professor se torne um critico de cinema, TV ou música. Mas, se ele deseja otimizar seu trabalho, é importante pensar num plano básico de formação, que pode ser expandido conforme a disponibilidade do professor (NAPOLITANO, 2008,p. 43).
\end{abstract}

A importância no planejamento de atividades com as mídias nas escola é, exatamente, para que elas tenham o resultado que se deseja, o qual esta associado a alfabetização científica, a desenvolvimento da criticidade do aluno através da construção do conhecimento, além da não reprodução de concepções errôneas da ciência-tecnologia. As últimas são vistas por alguns pesquisadores como um ponto chave para a educação científica, visto que, muitas vezes, elas são reforçadas pela própria educação científica, seja por ação ou omissão (CACHAPUZ et al., 2011).

Ao mesmo tempo em que destacam a importância da mídia nas escolas alguns participantes assumem um ponto de vista negativo em relação às mídias, das quais os alunos precisam ser alertados nas escolas quanto os "conteúdos manipuladores". Algumas respostas referentes a pergunta sobre a importância dos alunos saberem ler as mídias de maneira critica, ilustram essa visão:

"Para que não caiam nas armadilhas da mídia, tendo o conceito de discernir o que é proveitoso ou não" (Vinícius, 18 anos). 
Quando um aluno não ler a mídia de forma crítica ele fica vulnerável aos “bombardeios” de ideologias que ela nos joga. Com isso é importante que ele saiba ver e entender se é realmente isso o que a mídia nos passa ou se é apenas uma manipulação.

"Para que eles não sejam influenciados e também não acreditem no que a mídia quer, mas no que eles querem" (Luciana Eleres, 18 anos).

A colocação dos alunos denota certa preocupação com a "influência negativa" das mídias, o posicionamento é válido no sentido de acharem positiva a introdução das mídias de maneira crítica nas escolas, visto a presença constante e a influência das mesmas na sociedade e, consequentemente, na vida do aluno. Porém, tratar a mídia como algo muito ruim, ou como uma entidade que, tenta a todo custo, incutir uma ideologia maléfica pode tornar o discurso um tanto perigo. Nesse sentido, buscamos trabalhar a mídia de forma que a criticidade fosse algo real, ou seja, que os alunos percebessem a importante dos meios de comunicação, de sua influência na sociedade e que, por conta disso, é interessante discutí-los e permitir que os cidadãos sejam capazes da (re) leitura crítica para o entendimento do mundo e posicionamento diante dos fatos.

Ao escrever sobre a influência da mídia na vida de crianças e jovens, Moreira (2003) discute acerca do conceito de "sistema midiático cultural" quando fala sobre o processo de (re)criação e difusão de valores culturais criados pelas grandes corporações internacionais de mídia. Para o autor, esse "sistema midiático cultural", através da sua presença massiva, ação invasiva e constante, além do poder simbólico que possui estão transformando de maneira significativa nossa cultura.

Bourdieu (2011, p. 7) explica o poder simbólico como um "poder invisível, o qual só pode ser exercido com a cumplicidade daqueles que não querem saber que lhe estão sujeitos ou mesmo que o exercem". Nesse sentido o autor destaca que as relações de comunicação são sempre relações de poder, as quais dependem, diretamente, dos agentes e das instituições envolvidas nessas relações no que diz respeito ao poder material ou simbólico acumulado por elas.

Como os sistemas simbólicos (língua, arte, ciência, religião) são instrumentos de conhecimento e de comunicação podem exercer poder, principalmente, através da sua "função política de instrumentos de imposição ou de legitimação da dominação, que contribuem para assegurar a dominação de uma classe sobre outra (violência simbólica)” (BOURDIEU, 2001, p. 11). Com isso, as mídias, principalmente as grandes organizações de mídia, acabam por exercer um poder simbólico, o qual esta associado à forma pela qual os meios de comunicação tratam e/ou privilegia as funções políticas dos sistemas simbólicos. O que pode travar uma luta simbólica entre as diferentes classes sociais quando elas tentam impor seus interesses e as tomadas de posições ideológicas.

Portanto, como o discurso de que a influência das mídias como algo ruim é bastante comum, é importante que essa discussão seja aprofundada e trabalhada de forma que os discursos não sejam apenas pejorativos, mas que realmente abranja uma questão mais ampla e mais complexa sobre a real relação entre mídia e sociedade.

Alguns alunos já abordaram a importância da leitura crítica das mídias de outra forma, com a uma preocupação mais voltada para a prática social, a tomada de decisão e o posicionamento crítico diante dos acontecimentos.

“A grande importância é que os alunos abram seus conhecimentos [...]
e saibam debater com o mundo que estará a sua frente”. (Luciana, 17 anos)

\section{Categoria 3: abrangência da mídia-educação}

Muitos alunos admitiram através das respostas ao questionário que esse tema, mídia-educação, pode ser trabalhado por várias disciplinas curriculares devido a sua abrangência, ou seja, como as mídias são capazes de 
atingir diferentes públicos através de diversos assuntos, elas acabam por revelarem um potencial multidisciplinar o qual pode ser aproveitado na escola.

Napolitano (2008) destaca a possibilidade que de professores da área de humanidades, como história, geografia e português se sintam mais a vontade para trabalhar com meios, como a TV, por exemplo. Visto maior facilidade de aproximação entre programas de TV e seus conteúdos tradicionais. O autor também admite que, hoje, outras disciplinas já têm mais facilidade de fazer essa aproximação também.

Ao serem questionados sobre era possível o desenvolvimento de atividades com mídias com foco em outras disciplinas curriculares, alguns alunos responderam:

"Sim, pois usando a interdisciplinaridade o aluno se sentirá mais livre e o aprendizado será mais natural" (Emanuele, 17 anos).

"Com certeza. Já que a ciência abrange vários fatores, ela pode ser inserida em outras disciplinas de modo a comparar, interpretar, como por exemplo: em português podemos aplicar textos científicos para uma leitura, ou pedir para que montem um texto com seu entendimento sobre ciência; em história, podemos comparar como a ciência era no passado e como está agora [...] e assim com outras disciplinas” (Magda, 17 anos).

“Sim. Porque usando outros recursos na aprendizagem fica mais interessante” (Diana, 17 anos).

Alguns grupos de mídia já têm participação nas escolas através de projetos voltados para introduzir os meios de comunicação no cotidiano escolar dos estudantes. Caldas (2006) destaca que desde o início da década de 1990 jornais como O Globo e revistas como Carta Capital, são exemplos de grupos adeptos a esse tipo projeto voltados para as escolas. Além de revistas de divulgação científica, como por exemplo, a Ciência Hoje das Crianças que é distribuída pelo Ministério da Educação para escolas públicas de diferentes regiões do Brasil, através do Programa de Apoio à Educação da revista Ciência Hoje.

Quando tratamos de divulgação científica, a abrangência da mídia pode tomar grandes proporções, visto que a mídia é hoje um dos principais meio de divulgação da ciência que existe na sociedade da informação e é através da mídia que a maior parte das notícias a cerca da ciência e tecnologia chegam até as pessoas, inclusive, se tornam de conhecimento dos alunos.

Sendo assim, a divulgação científica se faz necessário, mas preparar as pessoas para a leitura e compreensão da ciência como ela aparece nas mídias também deve acontecer na mesma proporção. Nesse sentido Krasilchik e Marandino (2006) indicam que, hoje, é mais importante que o foco da alfabetização científica seja mais voltado para o público que se divulga do que para a produção científica em si.

Ao serem questionados sobre a contribuição de atividades com mídias para a alfabetização científica $100 \%$ dos alunos que responderam a pergunta (apenas 1 dos 10 alunos não respondeu), acreditam que sim, ou seja, a maioria dos alunos vêem a mídia como uma ferramenta que pode ser utilizada na sala de aula.

É importante destacar que os alunos do curso normal perceberam que a alfabetização científica é possível e interessante de ser desenvolvida desde as séries iniciais. Essa questão é defendida por pesquisadores que acreditam que o contato com as ciências desde a primeira infância é uma forma de estimular e despertar o interesse das crianças para as ciências

[...] é possível desenvolver uma alfabetização científica nas Séries Iniciais do Ensino Fundamental, mesmo antes do aluno dominar o código escrito. Por outro lado, esta alfabetização científica poderá auxiliar significativamente o processo de aquisição do código escrito, propiciando condições para que os alunos possam ampliar a sua cultura (LORENZETTI E DELIZOICOV, 2001, p. 3) 
Nesse sentido, os autores citados ainda sugerem alguns tipos de atividades que podem contribuir para a alfabetização científica nas séries iniciais se articulados com o planejamento escolar, visto que a escola sozinha não consegue transmitir tanto conhecimento científico. Dentre essas atividades há a consideração das mídias impressas e digitais-eletronicas como ferramenta pedagógica

\begin{abstract}
Dentre outras atividades possíveis de serem desenvolvidas destacamos as seguintes: o uso sistemático da literatura infantil, da música, do teatro e de vídeos educativos, reforçando a necessidade de que o professor pode, através de escolha apropriada, ir trabalhando os significados da conceituação científica veiculada pelos discursos contidos nestes meios de comunicação; explorar didaticamente artigos e demais seções da revista Ciência hoje das Crianças, articulando-os com aulas práticas; visitas a museus; zoológicos, indústrias, estações de tratamento de águas e demais órgãos públicos; organização e participação em saídas a campo e feiras de Ciências; uso do computador da Internet no ambiente escolar (LORENZETTI E DELIZOICOV, 2001, p.9).
\end{abstract}

Outros pesquisadores também destacam como as mídias podem ser empregadas para a produção de conhecimento importante para a formação de cidadanias ativas na sociedade. Nessa perspectiva, identifica-se a ampliação de diferentes iniciativas de alfabetização científica nos últimos anos, por meio de revistas científicas, jornais, produção de vídeos e aumento do número de centros de cultura científica (KRASILCHIK E MARANDINO, 2004, p. 28).

Chassot (2011) afirma que a importância da alfabetização científica nas escolas se faz necessária devido às mudanças que a globalização determinou através de uma inversão no fluxo do conhecimento. Para o autor hoje, ao contrário do que acontecia no tempo há décadas atrás, o mundo exterior invade a Escola e cria o que ela chama de “currículo ilegal”, portanto a Escola precisa ter um papel mais atuante na disseminação do conhecimento.

O autor discute ainda que uma parcela dessas invasões externas que chegam às salas de aula hoje são levadas pelos aluno e que, muitas vezes, superam os professores no que diz respeito ao acesso às fontes de informação. É comum que os alunos passem mais tempo na internet e/ou assistindo canais de TV a cabo do que os professores e, portanto chegam às escolas levando informações que são adquiridas através dos meios de comunicação dos quais eles estão em contato diariamente.

Assim como discutido, a importância da alfabetização científica se faz cada vez mais urgente no contexto social que estamos inseridos. Logo, a divulgação científica vem atrelada a essa discussão, já que pensar em alfabetizar cientificamente requer meios para que a produção científica chegue até as pessoas mais simples de forma inteligível e de preferência agradável e prazerosa. Sendo assim, discutir alfabetização e divulgação científica nas escolas se torna cada vez mais relevante, pois é preciso que o estudante seja visto como cidadão hoje, "e, nesse sentido, conhecer Ciência é ampliar a sua possibilidade presente de participação social e desenvolvimento mental, para assim viabilizar sua capacidade plena de exercício da cidadania” (BRASIL, 1998, p. 23).

\title{
3. CONSIDERAÇÕES FINAIS
}

Diante do cenário em que a sociedade da informação está inserida as discussões acerca da mídia-educação e de sua introdução de fato nas escolas, através da presente pesquisa, nos permite apontar uma potencialidade real para o desenvolvimento de atividades com mídias nas salas de aulas, as quais podem contribuir para a alfabetização científica e para a construção dialógica do conhecimento, através qual o aluno tem um papel central no processo de ensino e aprendizagem.

A pesquisa realizada com alunos do curso de formação de professores de nível médio se mostrou significativa por conta da possibilidade dessa discussão ser levada para as séries iniciais do ensino fundamental ao mesmo tempo em que tal discussão era introduzida e observada com alunos do ensino médio com boa aceitação da proposta entre eles. Apesar da utilização das mídias como ferramenta pedagógica tenha sido voltada para questões relacionadas ao ensino de ciências, divulgação e alfabetização científica, percebemos que tais ferra- 
mentas podem ser utilizadas por professores de diferentes disciplinas curriculares e com focos diferenciados de acordo com o objetivo que o professor deseja alcançar, por isso o planejamento do trabalho se mostra essencial para que esse tipo de atividade seja válida e contribua de forma efetiva para a aprendizagem.

Ao relatarem aspectos descritos nas três categorias encontradas a partir do questionário respondido pelos alunos observamos que, apesar de relatarem que as mídias podem ser usadas como ferramenta pedagógica a dificuldade com essa metodologia de ensino é real e, portanto, precisa ser bem trabalha e discutida. 


\section{REFERÊNCIAS}

BARDIN, L. Análise de Conteúdo. $4^{\mathrm{a}}$ Ed. Edições 70, 2010.

BARROQUEIRO, C.H et al. O uso das tecnologias de informação e comunicação no ensino de ciências e matemática: uma benção ou um problema? Anais do VII Encontro Nacional de Pesquisa em Educação em Ciências, Florianópolis, 2009.

BATISTA, R.A. Mídia \& Educação: teorias do jornalismo em sala de aula. Brasília; Thesaurus, 2007

BELLONI, M, L. O que é mídia-educação? Campinas: Autores Associados, 2005.

BERALDO, H. Contribuições da Química Inorgânica para a Química medicinal. Cadernos temáticos de Química Nova na Escola. Nº 6, 2005.

BOURDIEU, P. O poder simbólico. 15ª Ed. Rio de Janeiro; Bertrand Brasil, 2011.

BRASIL. Ministério da Educação. Parâmetros Curriculares Nacionais: Ciências da Natureza, Matemática e suas Tecnologias. Secretaria da Educação Média e Tecnológica - Brasília: MEC; SEMTEC, 1998.

BUCKINGHAM, D. After the death childhood: Growing up in the age of electronic media. Cambridge, England: Polity Press, 2000.

CACHAPUZ, A. et al. A necessária renovação do ensino de ciências. 2.ed. São Paulo: Cortez, 2011.

CALDAS, G. Mídia, escola e leitura crítica do mundo. Educação e Sociedade, Campinas, vol. 27, n. 94, p. 117-130, 2006.

CHASSOT, A. Alfabetização científica: questões e desafios para a educação. Ijuí: Unijuí, 2006.

CITELLI, A. Educação e mudanças: novos modos de conhecer In: Outras linguagens na escola. São Paulo. Cortez, 2004.

DELIZOICOV, D; ANGOTTI, J.A; PERNAMBUCO, M.M. Ensino de Ciências: fundamentos e métodos. 2ed. São Paulo: Cortez, 2007.

FILHO, J.F; LEMOS, J.F. Imperativos de conduta juvenil no século XXI: a “Geração Digital” na mídia impressa brasileira. Comunicação, mídia e consumo, vol 5 n 13 p. 11, 2008.

KRASILCHIK, M; MARANDINO, M. Ensino de ciências e cidadania. São Paulo: Moderna, 2006.

LORENZETTI, L. DELIZOICOV, D. Alfabetização científica no contexto das séries iniciais. Pesquisa em Educação em Ciências, vol. 0 3, n. 01, 2001.

MARTINHO, T. POMBO, L. Potencialidades das TIC no ensino das Ciências Naturais - um estudo de caso. Revista Electrónica de Enseñanza de las Ciências, Espanha, vol.8, n.2, p. 527-538, 2009.

MOREIRA, A.S. Cultura midiática e educação infantil. Educação e Sociedade, Campinas, vol. 24, n. 85, p. 1203-1235, 2003.

NAPOLITANO, M. Como usar a televisão na sala de aula. São Paulo. Contexto, 2008.

FREIRE, P. Pedagogia da autonomia: saberes necessários à prática educativa. São Paulo: Paz e Terra, 2010.

JARDIM, W.F. A evolução da atmosfera terrestre. Cadernos temáticos de Química Nova na Escola. Edição especial, 2001. 
OSBORNE, Jonathan. Towards a more social pedagogy in science education: the role of argumentation. Revista Brasileira de Pesquisa em Educação em Ciências. Vol. 7 No 1, 2007. Disponível em: http://revistas.if.usp.br/ rbpec/article/view/69/62.

OLIVEIRA, J.S de; MARTINS, M.M; APPELT, H.R. Trilogia: Química, Sociedade e Consumo. Química Nova na Escola, Vol. 32, N 3, 2010.

SILVA, L.A. ANDRADE, J.B. A Química a serviço da humanidade. Cadernos temáticos de Química Nova na escola. $N^{\circ} 5$ de 2003.

THIOLLENT, M. Metodologia da pesquisa-ação. São Paulo: Cortez, 2005.

UNESCO. Educação, um Tesouro a Descobrir. Relatório para a Unesco da Comissão Internacional sobre a Educação para o Século XXI. Porto: Asa. (Coord. de Jacques Delors), 1996. 